\title{
Painoon liittyvien ihanteiden ja käyttäytymisten vaikutus pitkän aikavälin terveyteen
}

Jokaisella ihmisellä on keho, joka painaa tietyn verran. Useimmiten paino mitataan laitteella, joka kertoo kuinka paljon maan vetovoima vetää puoleensa massaa. Tuo luku on yhteiskunnassamme saanut monenlaisia merkityksiä. Se ei ole vain laitteen ilmoittama luku, vaan se kertoo ihmisille itselleen sekä toisille usein myös paljon suurempia asioita. Se antaa merkityksiä siihen kuinka ihminen kokee itsensä, millaisia mahdollisia terveysriskejä hänen kehollaan ja mielellään on.

Painoon liittyy myös paljon asenteita, ihanteita ja käyttäytymisiä, jotka luovat merkityksiä ihmisen kyvyykkyydestä ja menestyksestä sekä työ- että henkilökohtaisessa elämässä, riippumatta yksilön todellisesta kyvykkyydestä tai potentiaalista. Painosta ja kehon koosta on tullut keskeinen tapa mitata itseä ja muita.

Lihavuudesta ja siihen liittyvistä liitännäissairauksista on tullut yksi maailman suurimmista kansanterveysongelmista. Perinteisesti lihavuutta ja painonmuutosta on tutkittu ulkoisten selittäjien, kuten sosiodemografisten tekijöiden avulla tai biolääketieteellisesti ja geenitutkimuksin. Vähemmän huomiota ovat saaneet erilaiset painoon liittyvät ihanteet ja käyttäytymiset, vaikka nämä ovat todennäköisesti merkittäviä painoon vaikuttavia tekijöitä erityisesti nuorilla aikuisilla.

Nuoren aikuisiän on osoitettu olevan erityisen kriittistä aikaa lihomiselle. Tuossa elämänvaiheessa ihmiset kokevat suuria elämänmuutoksia. Esimerkiksi siirtyminen opiskelijaelämästä työelämään ja perheen perustaminen sijoittuvat usein tähän elämänvaiheeseen. Painonnousu erityisesti nuoressa aikuisiässä on osoitettu olevan suuri riskitekijä suurentuneelle sairastuvuudelle sekä kuolleisuudelle.

Väitöskirjatutkimukseni keskittyy juuri tähän elämän kriittiseen ajanjaksoon. Kuitenkin käsiteltävänä olevat aiheet koskettavat kaikkia ih- misiä, koska jokaisella ihmisellä on keho, jonka paino muuttuu elämän varrella. Siten jokaisella ihmisellä on myös painoon liittyviä asenteita ja käyttäytymisiä, jotka vaikuttavat sekä fyysiseen että psyykkiseen terveyteen.

Aiheelta on lähes mahdotonta välttyä nykyyhteiskunnassamme, jossa ylipainoisten määrä kasvaa samalla kun sosiokulturaaliset kauneusihanteet ovat aina vain kauempana todellisuudesta aiheuttaen suurta ristiriitaa ihmisille.

Todennäköisesti myös sinulla on jokin luku, jota pidät ihannepainonasi. Onko tuo luku suurempi vai pienempi kuin tämänhetkinen todellinen painosi? Suurimmalla osalla tuo luku on pienempi.

Kun väitöskirjatutkimusta aloittaessani kirjoitin katsausartikkelin nuorten naisten sosiokultturaalisista painoihanteista, aloimme ohjaajani kanssa pohtimaan, että vaikka suurimmalla osalla on painoon liittyviä ihanteita, niin onko tuolla ihannepainolla todellista merkitystä ja vaikutusta pitkän aikavälin painonmuutokseen vai kertooko se ennemminkin vain siitä kuinka tyytymättömiä ihmiset ovat painoonsa?

Kävi ilmi, ettei ihannepainolla ollut merkitystä pitkän aikavälin painonmuutokseen, vaikka valtaosa nuorista naisista ja lähes puolet miehistä olivat tyytymättömiä painoonsa. Huolestuttava esiin noussut yksityiskohta väitöskirjatutkimuksessani on se havainto, että ne nuoret naiset, jotka ovat tyytyväisiä painoonsa ovat lähes alipainoisia eli lähes YKn nälkäavun piiriin kuuluvia. Tämä kertoo paljon vallitsevien kauneusihanteiden suhteesta terveyteen.

Suurin osa ihmisistä, riipumatta sukupuolesta tai iästä, kokevat kehonsa vääränlaiseksi. Lähes kaikki naiset ovat aikaisempien tutkimusten mukaan tyytymättömiä painoonsa ja kehoonsa läpi elämänsä. Miehillä kehotyytymättömyys on hiu- 
kan vähäisempää, mutta he näyttävät enenevissä määrin seuraavan naisten perässä. Kehotyytymättömyys itsessään on yhdistetty heikompaan itsetuntoon, masentuneisuuteen, ahdistukseen, epäterveellisiin painonhallintakeinoihin, häiriintyneeseen syömiskäyttäytymiseen, suurempaan riskiin lihoa ja sairastua syömishäiriöön.

Ihminen, joka kokee kehonsa vääränlaiseksi, tarttuu herkemmin yrityksiin muokata kehoaan paremmaksi -joksikin sellaiseksi mitä sen "pitäisi” olla. Meillä kaikilla ihmisillä on suuri tarve kuulua joukkoon, kokea olevamme hyväksyttyjä ja rakastettuja.

Vaikka lihavuuteen liittyvä häpeä on vähentynyt länsimaissa viime vuosina, on kehotyytymättömyys tuoreen katsaustutkimuksen mukaan yhteydessä suurentuneeseen lihomisen riskiin, epäterveellisiin painonhallintakeinoihin ja lisääntyneeseen häiriintyneeseen syömiskäyttäytymiseen. Vaikutus välittyy todennäköisesti uskomusjärjestelmien, itsensä arvostamisen ja oman kehon arvostamisen kautta.

Laihduttaminen onkin monelle tapa yrittää ratkaista ja hoitaa tätä tyytymättömyyttä omaa kehoa tai painoa kohtaan. Ratkaisuna laihduttaminen näyttää kuitenkin olevan ennemminkin paradoksi kuin todella toimiva keino ennaltaehkäistä tai hoitaa lisääntyvää painoa - etenkään pitkällä aikavälillä. Terveyden ja hyvinvoinnin laitoksen viimeisten tulosten mukaan yli puolet aikuisista on ylipainoisia tai lihavia ja lähes miljoona suomalaista raportoi laihduttavansa. Kansainvälisten tutkimusten mukaan noin puolet aikuisista laihduttaa jatkuvasti. Suurin osa laihduttajista kuitenkin lihoo takaisin lähtöpainoon ja useimmat saavat laihdutuksesta vielä pari upouutta kiloa kannettavakseen muistoksi uurastuksestaan.

Miten tämä on mahdollista, jos laihduttamisessa on vain puhtaasti kyse siitä että syö vähemmän kuin kuluttaa, kuten meille kaikille on opetettu?

Aluksi laihduttaminen voikin toimia erittäin hyvin. Se voi olla jopa euforinen kokemus. Kun ihminen laittaa itsensä tiukalle kuurille, alkaa rajoittamaan syömistään ja lisää liikuntaa mieliala kohenee ja pystyvyyden tunteet valtaavat olotilaa.

Kuitenkin liian tiukalle vedetty elimistö alkaa jonkin ajan päästä säätää aineenvaihduntaa pienemmälle selviytyäkseen. Samaan aikaan kaikista rajoituksista ja lisääntyneestä kuormituksesta aiheutuu useimmille lisääntyvää stressiä. Kun ke- ho on erittäin nälkäinen ja stressihormonit ovat koholla, niin sanotut "repsahdukset" alkavat useimmilla, ennemmin tai myöhemmin.

Usein niistä seuraa syyllisyyttä ja epäonnistumisen tunteita. Moni ajattelee, ettei omaa riittävästi tahdonvoimaa tai kokee, että hänessä itsessään on jotain vikana.

Laihduttamisen jälkeisen lihomisen myötä menetetään usein myös laihduttamisen mukana tapahtuneet positiiviset muutokset psyykkisessä hyvinvoinnissa. Kuitenkin moni yrittää vain uudestaan ja uudestaan, aina entistä tiukemmin ja kovemmin ajattellen, että...

"Jospa tämä ruokavalio ja tämä treeniohjelma olisivatkin ratkaisu ongelmaan?"

Tai että,

"Koska muut tässä onnistuvat, pitää minun selkeästi vain yrittää kovemmin”.

Laihduttamisen paradoksi on myös kannattavaa liiketoimintaa. Se on miljoonabisnestä. Valitettavasti voi kuitenkin olla, että ne verorahat, joita tuo bisnes kerryttää valtion kassaan ei riitä läheskään kattamaan niitä kustannuksia, joita tämä kuvio kokonaisuudessaan aiheuttaa pitkällä aikavälillä kaikkine liitännäissairauksineen.

Koska pysyvien laihdutustulosten saavuttaminen on vaikeaa, lihomisen ennaltaehkäisy on sekä yksilön että koko väestön näkökulmasta erittäin tärkeää. Halusin ymmärtää paremmin mitkä tekijät selittävät onnistumista painonhallinnassa. Aloimme tutkia, että onko meidän aineistossa nuoria naisia ja miehiä, jotka tässä onnistuvat ja mitkä tekijät ennustivat heidän onnistumistaan.

Kun perehdyin painonhallintatutkimuksiin, koin järkytyksen. Pitkäaikaisia väestöpohjaisia tutkimuksia on suhteellisen vähän ja tuolloin löysin ainoastaan yhden tutkimuksen, jossa oli tutkittu onnistunutta painonhallintaa ennen lihomista eli pitkällä aikavälillä normaalipainossa pysymistä. Väitöskirjan yhteenvetoa kirjoittaessani löysin toisen. Vallalla oleva tieto onnistuneesta painonhallinnasta perustuu siis tutkimuksiin, joissa on ensin laihdutettu ja sitten hallittu painoa.

Toisinsanottuna ohjeet ja neuvot liittyen painonhallintaan perustuvat pitkälti ihmisen tilaan, jossa on ensin laihdutettu. Tämä tila poikkeaa aika paljon ihan aineenvaihdunnallisesti elimistön tilasta verrattuna siihen, kun painossa ei ole tapahtunut suuria vaihteluita.

On osoitettu, että ruokahalua lisäävät hormonit ovat koholla jopa vuoden laihduttamisen 
jälkeen. Lisäksi on osoitettu, että erityisesti normaalipainoisilla laihduttaminen lisää riskiä lihomiselle. Tästä huolimatta laihduttaminen ei rajoitu vain heihin, joilla on tarve pudottaa painoaan terveydellisistä syistä.

Laihduttamisen myötä suhde syömiseen ja painoon vinksahtaa herkemmin niin, että samalla elämänpiiri pienenee ja psyykkinen kuormittuneisuus lisääntyvät. Ruoasta, syömisestä ja painosta tulee asioita, jota tulee tarkkailla ja hallita. Pienikin "repsahdus" voi merkitä sitä, että on ihmisenä täysin epäonnistunut. Ihminen alkaa taistelemaan biologiaansa vastaan, usein turvautuen tahdonvoimaansa. Ruoka ei ole enää ruokaa tai paino vain mittarin näyttämä luku, vaan hallinnan ja turvallisuuden tunteen kokemuksen välineitä. Tämä voi johtaa sotatilaan kehon ja sen normaalin biologisen toiminnan kanssa, jota on mahdotonta voittaa ilman oman fyysisen ja psyykkisen terveyden uhraamista. Tällöin ihmisen elämään on astunut syömishäiriö. Väestöstä kuitenkin vain murto-osa sairastuu syömishäiriöön.

Aloimme pohtia, että millaisia vaikutuksia väestotasolla ihmisen fyysiseen ja psyykkiseen terveyteen on silloin jos kipuileekin vain vähän tai vain ajoittain syömisen kanssa? Entä jos ei täytä syömishäiriön diagnostisia kriteereitä ja paino sekä suhde syömiseen näyttäytyvätkin ulkopuolisille täysin normaalilta? Onko häiriintynyt syömiskäyttäytyminen tuolloin harmitonta?

Usein syömisen ja kehonkuvan äärellä olevaan kipuiluun yhdistetään nuoret teini-iässä olevat tytöt. Häiriintynyttä syömiskäyttäytymistä on tutkittu eniten juuri teini-ikäisillä tytöillä ja jonkin verran myös pojilla. Vähemmän tiedetään häiriintyneen syömiskäyttäytymisen pitkäaikaisista seuraamuksista fyysiseen ja psyykkiseen terveyteen nuorilla aikuisilla. Erityisesti nuorilla miehillä näitä pitkäaikaisia yhteyksiä tunnetaan vielä varsin huonosti.

Väitöskirjassani tarkastellaan näiden ajatusten myötä herännyttä tutkimuskysmystä: Onko syömishäiriöitä lievemmällä oireilulla vaikutusta fyysiseen ja psyykkiseen terveyteen vielä nuoressa aikuisuudessa sekä naisilla ja miehillä vai loppuko tuon kipuilun negatiiviset pitkäaikaisvaikutukset nuoruuteen, jolloin ihmisen identiteetti ja moni muu asia hakee vielä paikkaansa?

Havaitsimme, että kipuilu ja siihen liittyvät seuraamukset eivät pääty teini-iän kanssa käsi kädessä, vaan häiriintyneellä syömiskäyttäytymisellä on kauaskantoisia seuraamuksia myös nuorten aikuisten naisten ja miesten fyysiseen ja psyykkiseen terveyteen.

Häiriintynyt syömiskäyttäytyminen on kuin harmaa pilvi, joka varjostaa elämää. Valitettavasti myös sateeseen sekä epämukavaan ja hiostavaan sadetakkiinkin tottuu, jos sitä käyttää joka päivä vuosien ajan.

Syömisen kanssa kipuiluun on usein haastavaa puuttua. Tähän vaikuttaa oireiluun liittyvä häpeä ja syyllisyys sekä se, että ihmiset ovat nykyään aika solmussa ja hukassa sen kanssa mikä on normaalia ja mikä häiriintynyttä, kun kanssaihmisten keskuudessa ja lehtien sivuilla esitellään toinen toistaan mahtavampia ruokavalioita, treeniohjelmia ja painonhallintavinkkejä.

Vuosikymmeniä on tieteen tekijät yrittäneetkin löytää sitä optimaalista ruokavaliota ja treeniohjelmaa, joiden myötä koittaisi onni ja autuus -lihavuusepidemia olisi vihdoin nujerrettu.

Valitettavasti sellaista käänteen tekevää yhtä selittävää tekijää tai kaikille sopivaa pakettiratkaisua ei näytä löytyvän. Toisaalta olisi mahtavaa, jos sellainen yksi selittävä tekijä voitaisiin löytää.

Toisaalta en usko, että ilmiössä, johon vaikuttaa koko elämä ja joka vaikuttaa koko elämään ja terveyteen, voisi edes olla olemassa yhtä ainoaa syytä ja ratkaisua. Monimutkaisiin ongelmiin tarvitaan usein moniulotteiset ratkaisut.

Tutkimusten mukaan näyttääkin sille, että yksilötasolla on oleellista löytää se itselle sopiva tapa syödä ja toteuttaa omassa elämäntilanteessaan hyvinvointia tukevia elämäntapoja. Se mikä toimii vieressäsi istuvalle henkilölle, ei välttämättä toimi sinulla tai ehkä juuri tämän hetkisessä elämäntilanteessasi.

Väitöskirjani mukaan väestötasolla onnistuneen painonhallinnan salaisuus näyttääkin löytyvän optimaalisen ruokavalion ja treeniohjelman sijaan säännöllisestä syömisestä ja laihduttamattomuudesta.

Ei kuulosta yhtä raflaavalta ja ihmeitä tekevältä kun erikoisia ruoka-aineita, rajoituksia ja selkeitä neuvoja sisältävät painonhallintavinkit.

Oman tien etsiminen, elämän ja elimistön tasapainon löytäminen on usein paljon haastavampaa kuin valmiiden ulkoapäin tulevien yksityiskohtaisten sääntöjen ja ohjeiden noudattaminen. Jotta ihminen voi pitkällä aikavälillä 
onnistuneesti hallita painoaan, tulee hänen katsoa omaan elämäänsä ja elimistöönsä vaikuttavia tekijöitä rehellisesti. Mitkä asiat eivät ole tasapainossa?

Tämä ei ole aina helppoa, varsinkaan ilman ammattiapua. Tästä syytä moni tarttuu erilaisiin pikavoittoihin ja kuureihin, valitettavan usein sillä kustannuksella, että kokee toistuvia epäonnistumisia ja ajaudutaan kauemmaksi hyvinvointia ja elämän mielekkyyttä tukevista asioista. Ajatellaan, että itsessä on vikaa, ei ratkaisussa.

Moni yrittää tosi paljon, mutta huomaakin ajan saatossa syömiskäyttäytymisensä muuttuneen vain entistä kaoottisemmaksi. Syöminen ja painonhallinta on "Kaikki tai ei mitään" elämää, jossa vaihtelee tiukat rajoittamisen ja hallinnan jaksot, joita seuraa ahminnat, alakulo ja ahdistus.

Suomalaisen väestötutkimuksen mukaan yli puolella nuorista aikuisista naisista ja miehistä täyttyy vähintään yksi ahmintahäiriön kriteereistä. Erityisesti ahmintakäyttäytymiseen ja ahmintahäiriöön liittyy suurentunut lihavuuden ja masentuneisuuden riski. Vaikka ahmintahäiriö, Binge Eating Disorder BED, on yleisin syömishäiriö sekä naisilla että miehillä, sen tunnistaminen on valitettavan puutteellista. Ahmintähäiriötä voidaan hoitaa tehokkaasti, mutta sairauden varhaista tunnistamista ja hoitoon hakeutumista estää usein oireiluun vahvasti liittyvä häpeä ja syyllisyys.

Koska on helpompaa ennaltaehkäistä painonnousua kuin laihduttaa, ahmintahäiriön varhainen tunnistaminen ja siihen rakentavasti puuttuminen on erittäin tärkeää perusterveydenhuollossa. Perusterveydenhuollossa ihminen tapaa yleensä kuitenkin henkilön, joka ei ole psykiatri. Siksi tulisikin olla käytössä helppokäyttöinen menetelmä ahmintahäiriön tunnistamiseksi. Väitöskirjatutkimukseni mukaan Eating Disorder Inventory -2 -kysely on toimiva työkalu tähän tarkoitukseen. Toimiva ja luotettava seulontatyökalu ei valitettavasti ratkaise koko ongelmaa.

Ahmintakäyttäytymistä omaavilla henkilöillä ja ahmintahäiriötä sairastavilla on ymmärrykseni mukaan usein paljon ikäviä kokemuksia tervey- denhuollosta. Moni joka on yrittänyt hakea apua, on saanut vain ohjeita laihduttamiseen.

Joillain ihmisillä tämä johtaa siihen, että painon, syömisen ja kehonkuvan kanssa kipuilun seurauksena elämä jää jossain määrin elämättä. Ylipäätään ylipainon ja lihavuuden hoito on usein hyvin laihdutuskeskeistä, vaikka tiedetään, että laihduttaminen lisää lihomisen, häiriintyneen syömiskäyttäytymisen ja syömishäiriöiden riskiä pitkällä aikavälillä.

Väitöskirjani tulosten ja johtopäätösten pohjalta tulevaisuudessa on tärkeää keskittyä kartoittamaan keinoja ensisijaisen painonhallinnan tukemiseksi, myönteisemmän kehonkuvan luomiseksi sekä ennaltaehkäisemään epäterveitä painoon liittyviä käyttäytymisiä, jotka ovat yhteydessä lihomiseen, häiriintyneeseen syömiskäyttäytymiseen sekä muihin painoon liittyviin terveysongelmiin. Lisäksi tarvitaan enemmän poikkitieteellistä tutkimusta, jotta ymmärretään paremmin tätä monimutkaista kokonaisuutta geenien, aineenvaihdunnan, psykologian, käyttäytymisen sekä sosiaalisten tekijöiden välisistä yhteyksistä. Tällaisella poikkitieteellisellä lähestymistavalla voisi olla mahdollista luoda lähestymistapoja ja keinoja ennaltaehkäistä ja hoitaa painoon liittyvää terveyttä siten, että todelliset taustalla vaikuttavat syyt tulisi huomioitua ilman, että psyykkinen hyvinvointi tai ja elämäntyytyväisyys kärsivät pitkällä aikavälillä.

\section{ULLA KÄRKKÄINEN \\ FT, laillistettu ravitsemusterapeutti \\ Helsingin yliopisto \\ Clinicum, Kansanterveystieteen laitos}

Terveystieteiden maisteri Ulla Kärkkäisen väitöskirja Weight-related ideals, behaviors and longterm health in young adulthood (Painoon liittyvät ihanteet, käyttäytymiset ja pitkän aikavälin terveys nuorilla aikuisilla) tarkastettiin Helsingin yliopiston tiedekunnassa 20.10.2018. Vastaväittäjänä toimi dosentti Susanna Lehtinen-Jacks Tampereen yliopistosta ja kustoksena akatemiaprofessori Jaakko Kaprio Helsingin yliopistosta. 
Adams KF, Leitzmann MF, Ballard-Barbash R ym. Body mass and weight change in adults in relation to mortality risk. Am J Epidemiol 2014 Jan 15;179(2):135-144. doi: 10.1093/aje/kwt254

Arabshahi S, Lahmann PH, Williams GM ym. Predictors of change in weight and waist circumference: 15 -year longitudinal study in Australian adults. Eur J Clin Nutr 2014 Mar;68(3):309-315. doi: 10.1038/ejen.2013.260.

Benton D, Young HA. Reducing Calorie Intake May Not Help You Lose Body Weight. Perspect Psychol Sci 2017 Sep;12(5):703-714. doi: 10.1177/1745691617690878.

Burke M, \& Heiland F. Evolving Societal Norms of Obesity. JAMA 2018 Jan 16;319(3):221-222. doi: 10.1001/jama.2017.18947.

DeWall CN, Deckman T, Pond RS ym. Belongingness as a core personality trait: how social exclusion influences social functioning and personality expression. J Pers 2011 Dec;79(6):1281-1314. doi: 10.1111/j.1467-6494.2010.00695.x.

Dulloo AG, Montani JP. Pathways from dieting to weight regain, to obesity and to the metabolic syndrome: an overview. Obes Rev 2015 Feb;16 Suppl 1:1-6. doi: 10.1111/obr.12250.

Dulloo AG, Jacquet J, Montani JP ym. How dieting makes the lean fatter: from a perspective of body composition autoregulation through adipostats and proteinstats awaiting discovery. Obes Rev 2015 Feb;16 Suppl 1:25-35. doi: 10.1111/obr.12253.

Goldschmidt AB, Wall M, Choo TH ym. Shared risk factors for mood-, eating-, and weightrelated health outcomes. Health Psychol 2016 Mar;35(3):245-252. doi: $10.1037 /$ hea0000283.

Haynes A, Kersbergen I, Sutin A ym. A systematic review of the relationship between weight status perceptions and weight loss attempts, strategies, behaviours and outcomes. Obes Rev. 2017 Dec 19. doi: 10.1111/obr.12634.

Järvelä-Reijonen E, Karhunen L, Sairanen E ym. High perceived stress is associated with unfavorable eating behavior in overweight and obese Finns of working age. Appetite 2016 Aug 1;103: 249-258. doi: 10.1016/j.appet.2016.04.023.

Karazsia BT, Murnen SK, Tylka TL. Is body dissatisfaction changing across time? A crosstemporal meta-analysis. Psychol Bull 2017 Mar;143(3):293-320. doi: $10.1037 /$ bul0000081.

Keel PK, Baxter MG, Heatherton TF ym. A 20-year longitudinal study of body weight, dieting, and eating disorder symptoms. J Abnorm Psychol 2007 May; 116(2):422-432. doi: 10.1037/0021-843X.116.2.422
Kärkkäinen U, Mustelin L, Raevuori A ym. Successful weight maintenance among young adults - A Tenyear prospective population study. Eat Behav 2018 Mar 7; 29:91-98. doi: 10.1016/j.eatbeh.2018.03.004.

Kärkkäinen U, Mustelin L, Raevuori A ym. Do Disordered Eating Behaviors have Long-Term Health-Related Consequences? Eur Eat Disord Rev 2018 Jan;26(1):22-28. doi: 10.1002/erv.2568.

Mustelin L, Kärkkäinen U, Kaprio J ym. The Eating Disorder Inventory in the screening for DSM-5 binge eating disorder. Eat Behav 2016 Aug; 22:145-8. doi: 10.1016/j.eatbeh.2016.06.011.

Kärkkäinen U, Mustelin L, Raevuori A ym. Ideals vs. reality: Is ideal weight associated with weight change in the general population? Obesity (Silver Spring) 2016 Apr;24(4):947-53. doi: 10.1002/oby.21417

Kärkkäinen U, Dadi Y, Keski-Rahkonen A. Nuorten naisten ihannepaino -sosiokulttuurisia ja terveydellisiä näkökohtia. Lääketieteellinen aikakausikirja Duodecim 2015;131(1):55-61.

Koponen P, Borodulin K, Lundqvist A ym. Terveys, toimintakyky ja hyvinvointi Suomessa. FinTerveys 2017-tutkimus 2018;4.

Korkeila M, Rissanen A, Sorensen TI ym. BMI, weight stability and mortality among adults without clinical co-morbidities: a 22-year mortality follow-up in the Finnish twin cohort. Obes Facts 2009;2(6):344-351. doi: $10.1159 / 000261416$

Larson N, Chen Y, Wall M ym. Personal, behavioral, and environmental predictors of healthy weight maintenance during the transition to adulthood. Prev Med 2018 Aug;113:80-90. doi: 10.1016/j.ypmed.2018.04.027

Logel C, Stinson DA, Brochu PM. Weight Loss Is Not the Answer: A Well-being Solution to the Obesity Problem. Social and Personality Psychology Compass 2015;9(12):678-695. doi: $10.1111 / \mathrm{spc} 3.12223$

Lynch E, Liu K, Wei GS ym. The relation between body size perception and change in body mass index over 13 years: the Coronary Artery Risk Development in Young Adults (CARDIA) study. Am J Epidemiol 2009 Apr 1;169(7):857-866. doi: 10.1093/aje/kwn412

McCabe MP, Ricciardelli LA. Body image dissatisfaction among males across the lifespan: a review of past literature. J Psychosom Res 2004 Jun;56(6):675-685. doi: 10.1016/S0022-3999(03)00129-6

Montani JP, Schutz Y, Dulloo AG. Dieting and weight cycling as risk factors for cardiometabolic diseases: who is really at risk? Obes Rev 2015 Feb;16 Suppl 1:7-18. doi: 10.1111/obr.12251 
Mustelin L, Bulik CM, Kaprio J ym. Prevalence and correlates of binge eating disorder related features in the community. Appetite 2017 Feb 1;109:165171.

doi: 10.1016/j.appet.2016.11.032

Mustelin L, Kaprio J, Keski-Rahkonen A. Beyond the tip of the iceberg: Adolescent weight development of women and men with features of binge eating disorder. Eat Behav 2018 Aug;30:83-87. doi: 10.1016/j.eatbeh.2018.06.004

National Task Force on the Prevention and Treatment of Obesity. Dieting and the development of eating disorders in overweight and obese adults. Arch Intern Med 2000 Sep 25;160(17):2581-2589.

Neumark-Sztainer D. Integrating messages from the eating disorders field into obesity prevention. Adolesc Med State Art Rev. 2012;23(3):529-43.

Neumark-Sztainer D, Wall M, Guo J ym. Obesity, disordered eating, and eating disorders in a longitudinal study of adolescents: how do dieters fare 5 years later? J Am Diet Assoc 2006 Apr;106(4):559-568. doi: 10.1016/j.jada.2006.01.003

Obesity: preventing and managing the global epidemic. Report of a WHO consultation. World Health Organ Tech Rep Ser 2000;894:i-xii, 1-253.

Pietilainen KH, Saarni SE, Kaprio J ym. Does dieting make you fat? A twin study. Int J Obes (Lond) 2012 Mar;36(3):456-464. doi: 10.1038/ijo.2011.160

Ramage S, Farmer A, Eccles KA ym. Healthy strategies for successful weight loss and weight maintenance: a systematic review. Appl Physiol Nutr Metab 2014 Jan;39(1):1-20.

doi: 10.1139/apnm-2013-0026

Runfola CD, Von Holle A, Trace SE ym. Body dissatisfaction in women across the lifespan: results of the UNC-SELF and Gender and Body Image (GABI) studies. Eur Eat Disord Rev 2013 Jan;21(1):52-59. doi: 10.1002/erv.2201
Santos I, Sniehotta FF, Marques MM ym. Prevalence of personal weight control attempts in adults: a systematic review and meta-analysis. Obes Rev 2017 Jan;18(1):32-50.

doi: 10.1111/obr.12466

Slof-Op 't Landt MC, van Furth EF, van Beijsterveldt CE ym. Prevalence of dieting and fear of weight gain across ages: a community sample from adolescents to the elderly. Int J Public Health 2017 Feb 20. doi: 10.1007/s00038-017-0948-7

Sonneville KR, Horton NJ, Micali N ym. Longitudinal associations between binge eating and overeating and adverse outcomes among adolescents and young adults: does loss of control matter? JAMA Pediatr 2013 Feb;167(2):149-155.

doi: 10.1001/2013.jamapediatrics.12.

Sorensen TI, Rissanen A, Korkeila M ym. Intention to lose weight, weight changes, and 18-y mortality in overweight individuals without co-morbidities. PLoS Med 2005 Jun;2(6):e171. doi: 10.1371/journal.pmed.0020171

Stice E, Cameron RP, Killen JD ym. Naturalistic weight-reduction efforts prospectively predict growth in relative weight and onset of obesity among female adolescents. J Consult Clin Psychol 1999; 67: 967-974.

Tomiyama AJ, Mann T, Vinas D ym. Low calorie dieting increases cortisol. Psychosom Med 2010 May;72(4):357-364. doi: 10.1097/PSY.0b013e3181d9523c

Wing RR, Phelan S. Long-term weight loss maintenance. Am J Clin Nutr 2005 Jul;82(1 Suppl):222S-225S. doi: 10.1093/ajcn/82.1.222S

Weinberger NA, Kersting A, Riedel-Heller SG ym. Body Dissatisfaction in Individuals with Obesity Compared to Normal-Weight Individuals: A Systematic Review and Meta-Analysis. Obes Facts 2016;9(6):424-441. doi: $10.1159 / 000454837$ 